\title{
RNA applications for endophytic research
}

\author{
J.C. Polonio ${ }^{1}$, A.D. Polli ${ }^{1}$, J.L. Azevedo ${ }^{2}$ and J.A. Pamphile ${ }^{1}$ \\ ${ }^{1}$ Departamento de Biotecnologia, Genética e Biologia Celular, \\ Universidade Estadual de Maringá, Maringá, PR, Brasil \\ 2Departamento de Genética, Escola Superior de Agricultura "Luiz de Queiroz", \\ Piracicaba, SP, Brasil \\ Corresponding author: J.A. Pamphile \\ E-mail: prof.pamphile@gmail.com / japamphile@uem.br
}

Genet. Mol. Res. 15 (3): gmr.15038879

Received June 14, 2016

Accepted July 22, 2016

Published September 19, 2016

DOI http://dx.doi.org/10.4238/gmr.15038879

Copyright (C) 2016 The Authors. This is an open-access article distributed under the terms of the Creative Commons Attribution ShareAlike (CC BY-SA) 4.0 License

\begin{abstract}
Endophytic microorganisms, mainly bacteria and fungi, have intrinsic relationships with the host plants, involving complex chemical and genetic communication networks. The relationship among these organisms involves the development of regulatory mechanisms of gene expression that control their development and response to different interactions. Although RNA molecules are already being used in studies of microorganism diversity and taxonomy, for example, using comparisons of rRNA regions, they may also be useful tools in the exploration of gene regulation and modeling of other molecules, such as the analysis of microRNA and small interfering RNAs. Transcriptional profile analyses are capable of providing robust information on biosynthetic pathways, genes involved in the interaction and differential production of metabolites by endophytes, using RNA-seq approaches. In-depth studies of RNA types and their functions in endophytes may provide valuable information that can be used for biotechnological manipulation of microorganisms to produce metabolites, bioremediation, biological
\end{abstract}

Genetics and Molecular Research 15 (3): gmr.15038879 
control of pathogens, and decrease plant diseases, among other economically important applications. Our study highlights the present state of knowledge of studies involving endophytes, RNA molecules, and future perspectives.

Key words: Endophytic microorganisms; snRNA; siRNA; RNA molecular taxonomy

\section{INTRODUCTION}

The use of molecular genetic tools for diversity and taxonomic studies of living organisms has been extensively discussed by Woese and collaborators (Woese and Fox, 1977; Woese et al., 1990). Using comparisons of rRNA regions in different living organisms, they proposed a higher taxon for classification and grouping, called "Domain", which is divided into three, Bacteria, Archaea, and Eucarya (Woese and Fox, 1977; Woese et al., 1990). The development of new technologies, including DNA sequencing and bioinformatics, has increased the analyses' robustness using rRNA as barcode regions for taxonomic purposes. This methodological progress turned out to be very important to endophytic studies, since many microorganisms cannot be produced by sexual structures in in vitro conditions and, thus, taxonomic identification is impaired.

Microorganisms are highly interesting for biotechnological studies because bacteria and fungi often establish intrinsic relationships with host plants, involving complex chemical and genetic communication networks (Kusari et al., 2012; Thiebaut et al., 2015). The interaction, which may be mutualistic or symbiotic, requires balanced antagonism states. The endophytic microorganism has to avoid the defense responses of its host before being disabled by the plant's toxic metabolites, resulting in an asymptomatic colonization in which an antagonism balance between the endophyte and the host occurs (Kusari et al., 2012). This interaction depends on genetic, epigenetic, and metabolic controls by both plant and endophyte (Carvalho et al., 2016). Apart from taxonomic studies, RNA molecules involved in the genetic regulation and modeling of other molecules, such as microRNA (miRNA) and small interfering RNA (siRNA), may represent a great niche for biotechnological approaches and in the exploration of endophyte and plant host interactions, especially those of economic importance. The present study is a literature search aiming highlights the state-of-the-art study involving endophytes, RNA molecules, future perspectives to biotechnological applications, focusing the interactions between plants and endophytes.

\section{MATERIAL AND METHODS}

Scientific articles were electronically searched in the PubMed (http://www.ncbi.nlm. nih.gov/pubmed), Google Scholar (https://scholar.google.com.br), Science Direct (http:// www.sciencedirect.com), and Web of Science (https://www.webofknowledge.com/), using various combinations of key words, including "snRNA endophyte", "siRNA endophyte", "RNA endophyte", and others (Table 1). The articles were analyzed individually in order to mining the most important and latest information about endophyte and plant interactions and RNA molecules.

Genetics and Molecular Research 15 (3): gmr.15038879 


\section{RESULTS}

The results of our literature search are shown in Table 1. Most articles $(>80 \%)$ were diversity, taxonomy, and phylogenetic studies using rRNA (Figure 1). The 5.8S gene was the most commonly studied region in these papers. Other molecules, such as small noncoding RNAs (snRNAs), were found only in a reduced number of studies. These articles were mostly related to plant-microbe interaction studies, such as RNA-seq, and differential expression of genes related to endophytism and phytopathogenicity.

Table 1. Search results of studies related with RNA and endophytes (until May 2016).

\begin{tabular}{l|c|c|c|c}
\hline \multirow{2}{*}{ Key words } & \multicolumn{4}{|c}{ Search tools/databases } \\
\cline { 2 - 5 } & PubMed & Science Direct & Web of Science & Google Scholar \\
\hline snRNA endophyte & 3 & 0 & 0 & 59 \\
\hline microRNA endophytes & 1 & 12 & 3 & 932 \\
\hline microRNA endophytic & 3 & 44 & 2 & 978 \\
\hline RNAi endophytes & 1 & 68 & 3 & 1320 \\
\hline RNAi endophytic & 4 & 71 & 558 & 1390 \\
\hline rRNA endophytic & 395 & 802 & 333 & 14,900 \\
\hline rRNA endophyte & 82 & 711 & 2 & 515 \\
\hline siRNA endophytic & 2 & 41 & 7 & 764 \\
\hline RNA-seq endophytic & 3 & 40 & 10 & \\
\hline RNA-seq endophyte & 3 & 52 & & 764 \\
\hline
\end{tabular}

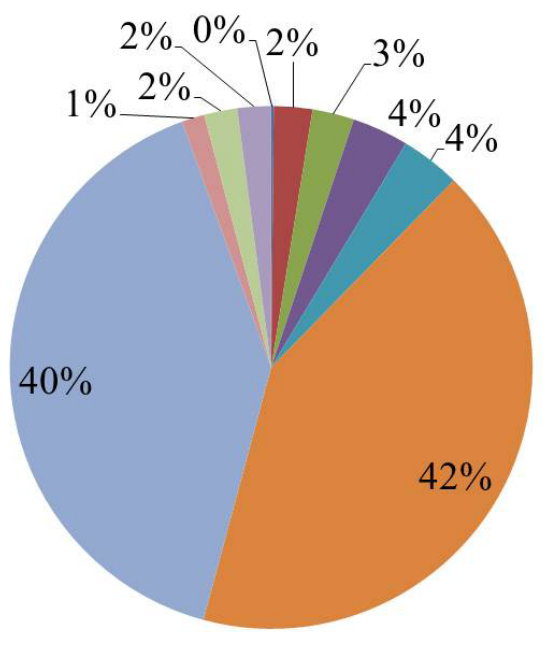

- snRNA endophyte

miRNA endophytes

miRNA endophytic

- RNAi endophytes

- RNAi endophytic

rRNA endophytic

rRNA endophyte

siRNA endophytic

RNA-seq endophytic

RNA-seq endophyte

Figure 1. Graphical representation of total search results from databases and search tools using the key words listed in Table 1.

\section{DISCUSSION}

\section{Taxonomic purposes}

rRNA encoding regions were first used for taxonomic purposes and are still greatly employed to date. Techniques, such as amplified ribosomal DNA restriction analysis with 
posterior DNA sequencing, could make possible molecular identification of microorganisms based on DNA barcode comparisons.

The eukaryotic rRNA cistron consists of 18S, 5.8S, and 28S rRNA genes transcribed as a unit by RNA polymerase I. Post-transcriptional processes then split the cistron and remove two internal transcribed spacers (ITSs), which, including the 5.8S gene, are usually referred to as the ITS region. The $18 \mathrm{~S}$ nuclear ribosomal small subunit rRNA gene is commonly used in phylogenetic studies, and, although its homolog (16S) is often employed as a species diagnostic paradigm for bacteria (Bredow et al., 2015), 18S has fewer hypervariable domains in fungi. The 28S nuclear ribosomal large subunit rRNA gene sometimes discriminates species alone or with ITS. However, 5.8S rRNA is the main region used for fungal taxonomic purposes. White et al. (1990) detailed primers, such as ITS1, ITS4, and others, that may be used to amplify the ITS1-5.8S-ITS2 region in fungi. This region represents a robust tool in identification of genus for fungus (Rhoden et al., 2013). Further, the 5.8S rRNA regions are flanked by ITSs and have several copies in the eukaryote genome. The gene encoded by $5.8 \mathrm{~S}$ rRNA is highly conserved into genus, but the ITS regions feature a high rate of mutation, presenting variation between species and/or populations. Consequently, the region has become one of the main factors for taxonomic purposes.

Moreover, 16S rRNA provides trustworthy results for bacterial identification (Bredow et al., 2015). Rhoden et al. (2015) identified 16 endophytic bacteria living on leaves of Trichilia elegans (Meliaceae), using sequencing and phylogenetic analyses. Several studies have isolated and identified endophytic bacteria of medicinal plants with the 16S rRNA gene used as a tool in molecular identification (Compant et al., 2010; de Oliveira Costa et al., 2012; Miguel et al., 2013; Castro et al., 2014; Rhoden et al., 2015).

In a diversity study, Winston et al. (2014) employed sequencing of 16S rRNA using the Illumina platform and revealed bacterial communities of Pseudomonas, Cellvibrio, Oxalobacteraceae, Xanthomonadaceae, Actinomycetales, and Sphingobacteriales in different varieties of Cannabis roots. Furthermore, they also demonstrated that bacterial communities preferred rhizospheric over non-rhizospheric soil regions, when there was a reduction of abundance in Acidobacteria associated with an increase of Proteobacteria and Actinobacteria in the rhizosphere. The study revealed that bacterial communities were specific for each habitat type, such as soil type, farming, and region (rhizospheric, endorhizospheric, and not-rhizospheric).

Schoch et al. (2012) emphasized the utilization of ITS regions as the main fungal barcode, but they also highlighted the need for using additional barcodes based on the taxonomic group studied. The identification of microorganisms based on DNA barcoding depends on factors such as the reliability of databases; expertise in manipulation and DNA sequencing; and knowledge about working with sequences, phylogenies, and bioinformatic tools.

\section{Plant-microbe interactions: RNA-seq and transcriptional profiles}

The interaction between plants and microorganisms involves several systems of recognition and selection of pathogens and endophytic microorganisms. This includes the response of the plant immune system as the perception of elicitors, as well as pattern molecular recognition receptors of both plants and microbes. The recognition of a pathogen triggers a cascade of signal transductions that activates the plant defense pathways. The latter may include the production of reactive oxygen species, synthesis of secondary bioactive compounds and phytohormones, and alterations of the plant cell wall (van Loon et al., 2006;

Genetics and Molecular Research 15 (3): gmr.15038879 
Robert-Seilaniantz et al., 2011; Underwood, 2012; Scheler et al., 2013; Thiebaut et al., 2015). The establishment of endophyte conditions depends on the microorganism's capacity to establish a balanced antagonism involving secondary metabolites, protein/enzymatic activities, and genetic controls, principally at the transcriptional levels (Figure 2) (Zhang et al., 2010; Kusari et al., 2012; Thiebaut et al., 2015; Weiberg et al., 2015).

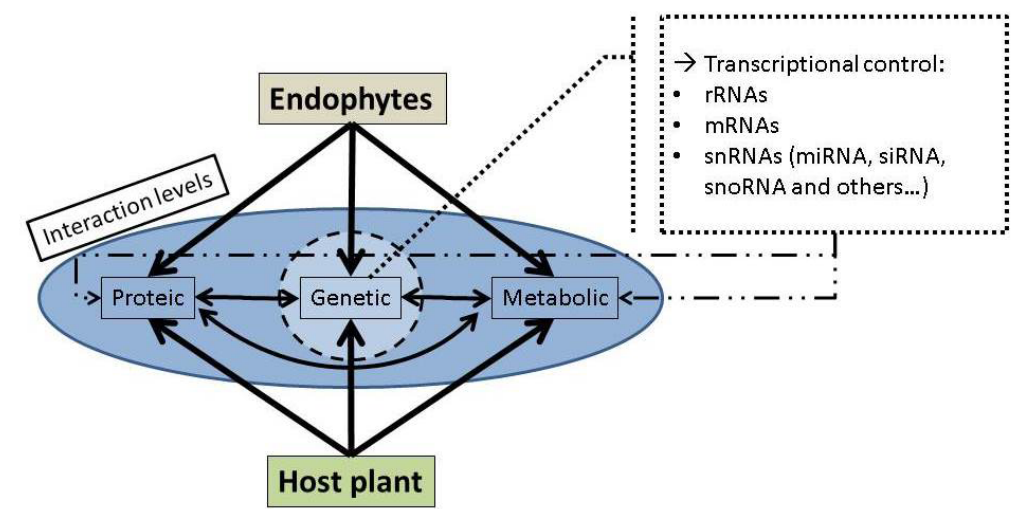

Figure 2. Schematic of network interactions between endophytes and host plants. The symbiotic/mutualistic comportment of endophytes depends on complex proteic, genetic, and metabolic interactions. Specifically, for genetic factors, the transcriptional control can be considered the key for several of the biosynthetic routes and the involvement of snRNAs is an underexplored niche for plant-endophyte and biotechnological studies.

Owing to constant plant-microbe interactions, the organisms need a fine-tuned regulation of gene expression to control the development of these interactions (Fujita et al., 2006; Thiebaut et al., 2015). According to Thiebaut et al. (2015), the action of endogenous snRNA, that could be siRNA or miRNA, is the main mechanism that regulates gene expression in eukaryotes.

Carvalho et al. (2016) considered the interaction between the plant, microbe, rhizoplane, and rhizosphere as a "single coordinated unit with dynamic components". This dynamic unit requires adaptive responses of both plants and microbes for balanced growth. The analysis of transcriptional profiles may provide robust information with prior knowledge of biosynthetic pathways and genes involved.

The RNA-seq approach provides valuable information on plant-endophyte interactions, and others such as differential metabolite production by endophytes. Zhang et al. (2010) related the differential expression of genes linked to the loline alkaloid biosynthesis, a natural insecticidal compound produced by the grass endophyte Epichloë festucae. The authors compared RNA sequencing data under different growth conditions and reported that substrate availability controlled loline alkaloid levels, with little or no involvement of transcriptional control.

In another example, the transcriptional profile of the dark septate endophyte Exophiala pisciphila under cadmium-stress conditions demonstrated a total of 575 differentially expressed genes, where $40 \%$ of the genes were involved in 10 well-known heavy metal-tolerant pathways (Zhao et al., 2015). Therefore, transcriptional profiles provide valuable information that may describe the behavior of endophytes under different conditions. This information may help us utilize fungi and bacteria as biotechnological tools for products and services. 


\section{RNA interference (RNAi) and future applications}

Several studies have found mycoviruses in endophytic fungi. The presence or absence in some fungus strains may indicate the resistance of specific fungal lineages to mycovirus infection. Host plants that contain endophytes infected by these viruses may cause plant adaptation to extreme environments, such as heat tolerance. On the other hand, a virus-infected fungus may result in a phytopathogenic life style relationship with the host plant (Márquez et al., 2007; Herrero et al., 2009; Asensio et al., 2013; Rosseto et al., 2016). Rosseto et al. (2016) analyzed endophytic and phytopathogenic fungal strains of Colletotrichum (Glomerella) and showed the presence of mycoviruses in one phytopathogenic strain using double-stranded RNA (dsRNA) analyses and transmission electron microscopy. Previous results indicate that the virulence of the fungal species may be related to mycovirus infection. Since other studies have reported similar results (Dalzoto et al., 2006; Figueirêdo et al., 2012; Zhong et al., 2014) and taking the behavior into consideration, mycoviruses may be considered a biocontrol tool against pathogen virulence.

However, one of the eukaryotic mechanisms against viral infection and expression control is RNAi, which is a reverse-genetic technique that permits the ablation of mRNA by the introduction of complementary, dsRNA through cellular mechanisms. According to Thiebaut et al. (2015), siRNA and miRNA act as specific repressors of target gene expression through DNA methylation, histone modification, cleavage of the target transcript at the posttranscriptional level, or by inhibition of translation.

Tinoco et al. (2010) demonstrated the phenomenon of RNAi on engineered tobacco plants expressing an siRNA for silencing the GUS gene. The authors also used the fungus Fusarium verticillioides that had been engineered to express the GUS gene, which, after the inoculation of mycelial cells on tobacco plants, resulted in the abolishment of $F$. verticillioides GUS expression by plant siRNA-GUS. Since endophytic microorganisms penetrate and inhabit the interior of the host plant without causing damage (Pamphile and Azevedo, 2002), they may inhabit inter- and intracellular spaces (García et al., 2012) and systemically dissipate the host tissue through the phloem and xylem (Hallmann et al., 1997; Mattos et al., 2008). In this way, they may interact with the host plant and other organisms, such as insects and pathogens, in a complex cell-to-cell genetic system communication. In other words, in the future, the siRNA from endophytes may be an alternative against viruses and other pests, such as insects and microorganisms (Burand and Hunter, 2013), in important crops. So, these properties of siRNA may favor the use of natural or transgenic endophytic strains as "siRNA deliverers" in contaminated plants, aimed at biological control, reduction of liabilities, and reduction of agrochemical use. As such, it is a relevant underexplored niche in endophytic studies.

Limitations in studies and applications of RNA from endophytes are mostly related to fledgling knowledge of the plant-endophyte interactions at the genetic level. Moreover, the genetic focus of transcription factors associated with endophyte-host relationships is still incipient and gene expression studies of such associations require novel technologies such as next-generation sequencing.

To conclude, scientific studies involving RNA molecules and endophytic microorganisms are beginning to go beyond taxonomic and diversity studies towards analyses of the expression of several genes under different conditions. In the future, knowledge and control of the transcriptome and metabolome of these specific microorganisms may forward new approaches to applied biocontrol, production of new metabolites, bioremediation, and make possible siRNA delivery against plant viruses and other pathogens.

Genetics and Molecular Research 15 (3): gmr.15038879 


\section{Conflicts of interest}

The authors declare no conflict of interest.

\section{ACKNOWLEDGMENTS}

The authors would like to thank Coordenação de Aperfeiçoamento de Pessoal de Nível Superior (CAPES) for the scholarship, and CNPq (\#311534/2014-7 and \#447265/20148) and Fundação Araucária (\#276/2014) for funding.

\section{REFERENCES}

Asensio NH, Máquez SS and Zabalgogeazcoa I (2013). Mycovirus effect on the endophytic establishment of the entomopathogenic fungus Tolypocladium cylindrosporum in tomato and bean plants. BioControl 58: 225-232. http:// dx.doi.org/10.1007/s10526-012-9476-9

Bredow C, Azevedo JL, Pamphile JA, Mangolin CA, et al. (2015). In silico analysis of the 16S rRNA gene of endophytic bacteria, isolated from the aerial parts and seeds of important agricultural crops. Genet. Mol. Res. 14: 9703-9721. http://dx.doi.org/10.4238/2015.August.19.3

Burand JP and Hunter WB (2013). RNAi: future in insect management. J. Invertebr. Pathol. 112 (Suppl): S68-S74. http:// dx.doi.org/10.1016/j.jip.2012.07.012

Carvalho TL, Ballesteros HG, Thiebaut F, Ferreira PC, et al. (2016). Nice to meet you: genetic, epigenetic and metabolic controls of plant perception of beneficial associative and endophytic diazotrophic bacteria in non-leguminous plants. Plant Mol. Biol. 90: 561-574. http://dx.doi.org/10.1007/s11103-016-0435-1

Castro RA, Quecine MC, Lacava PT, Batista BD, et al. (2014). Isolation and enzyme bioprospection of endophytic bacteria associated with plants of Brazilian mangrove ecosystem. Springerplus 3: 382. http://dx.doi.org/10.1186/2193-1801$\underline{3-382}$

Compant S, Clément S and Sessitsch A (2010). Plant growth-promoting bacteria in the rhizo- and endosphere of plants: their role, colonization, mechanisms involved and prospects for utilization. Soil Biol. Biochem. 42: 669-678. http:// dx.doi.org/10.1016/j.soilbio.2009.11.024

Dalzoto PR, Glienke-Blanco C, Kava-Cordeiro V, Ribeiro JZ, et al. (2006). Horizontal transfer and hypovirulence associated with double-stranded RNA in Beauveria bassiana. Mycol. Res. 110: 1475-1481. http://dx.doi. org/10.1016/j.mycres.2006.08.009

de Oliveira Costa LE, de Queiroz MV, Borges AC, de Moraes CA, et al. (2012). Isolation and characterization of endophytic bacteria isolated from the leaves of the common bean (Phaseolus vulgaris). Braz. J. Microbiol. 43: 15621575. http://dx.doi.org/10.1590/S1517-83822012000400041

Figueirêdo LC, Figueiredo GS, Giancoli ACH, Tanaka FAO, et al. (2012). Detection of isometric, dsRNA-containing viral particles in Colletotrichum gloeosporioides isolated from cashew tree. Trop. Plant Pathol. 37: 142-145. http://dx.doi. org/10.1590/S1982-56762012000200007

Fujita M, Fujita Y, Noutoshi Y, Takahashi F, et al. (2006). Crosstalk between abiotic and biotic stress responses: a current view from the points of convergence in the stress signaling networks. Curr. Opin. Plant Biol. 9: 436-442. http:// dx.doi.org/10.1016/j.pbi.2006.05.014

García A, Rhoden SA, Rubin Filho CJ, Nakamura CV, et al. (2012). Diversity of foliar endophytic fungi from the medicinal plant Sapindus saponaria L. and their localization by scanning electron microscopy. Biol. Res. 45: 139-148. http:// dx.doi.org/10.4067/S0716-97602012000200006

Hallmann J, Quadt-Hallmann A, Mahaffee WF and Kloepper JW (1997). Bacterial endophytes in agricultural crops. Can. J. Microbiol. 43: 895-914. http://dx.doi.org/10.1139/m97-131

Herrero N, Sánchez Márquez S and Zabalgogeazcoa I (2009). Mycoviruses are common among different species of endophytic fungi of grasses. Arch. Virol. 154: 327-330. http://dx.doi.org/10.1007/s00705-008-0293-5

Kusari S, Hertweck C and Spiteller M (2012). Chemical ecology of endophytic fungi: origins of secondary metabolites. Chem. Biol. 19: 792-798. http://dx.doi.org/10.1016/j.chembiol.2012.06.004

Márquez LM, Redman RS, Rodriguez RJ and Roossinck MJ (2007). A virus in a fungus in a plant: three-way symbiosis required for thermal tolerance. Science 315: 513-515. http://dx.doi.org/10.1126/science.1136237

Mattos KA, Pádua VL, Romeiro A, Hallack LF, et al. (2008). Endophytic colonization of rice (Oryza sativa L.) by the

Genetics and Molecular Research 15 (3): gmr.15038879 
diazotrophic bacterium Burkholderia kururiensis and its ability to enhance plant growth. An. Acad. Bras. Cienc. 80: 477-493. http://dx.doi.org/10.1590/S0001-37652008000300009

Miguel PSB, Delvaux JC, Oliveira MNV, Monteiro LCP, et al. (2013). Diversity of endophytic bacteria in the fruits of Coffea canephora. Afr. J. Microbiol. Res. 7: 586-594. http://dx.doi.org/10.5897/AJMR12.2036

Pamphile JA and Azevedo JL (2002). Molecular characterization of endophytic strains of Fusarium verticillioides (= Fusarium moniliforme) from maize (Zea mays. L). World J. Microbiol. Biotechnol. 18: 391-396. http://dx.doi. org/10.1023/A:1015507008786

Rhoden SA, Garcia A, Azevedo JL and Pamphile JA (2013). In silico analysis of diverse endophytic fungi by using ITS15,8S-ITS2 sequences with isolates from various plant families in Brazil. Genet. Mol. Res. 12: 935-950. http://dx.doi. org/10.4238/2013.April.2.10

Rhoden SA, Garcia A, Santos e Silva MC, Azevedo JL, et al. (2015). Phylogenetic analysis of endophytic bacterial isolates from leaves of the medicinal plant Trichilia elegans A. Juss. (Meliaceae). Genet. Mol. Res. 14: 1515-1525. http:// dx.doi.org/10.4238/2015.February.20.7

Robert-Seilaniantz A, Grant M and Jones JD (2011). Hormone crosstalk in plant disease and defense: more than just jasmonate-salicylate antagonism. Annu. Rev. Phytopathol. 49: 317-343. http://dx.doi.org/10.1146/annurevphyto-073009-114447

Rosseto P, Costa AT, Polonio JC, da Silva AA, et al. (2016). Investigation of mycoviruses in endophytic and phytopathogenic strains of Colletotrichum from different hosts. Genet. Mol. Res. 15: 15017651 http://dx.doi. org/10.4238/gmr.15017651.

Scheler C, Durner J and Astier J (2013). Nitric oxide and reactive oxygen species in plant biotic interactions. Curr. Opin. Plant Biol. 16: 534-539. http://dx.doi.org/10.1016/j.pbi.2013.06.020

Schoch CL, Seifert KA, Huhndorf S, Robert V, et al.; Fungal Barcoding Consortium; Fungal Barcoding Consortium Author List (2012). Nuclear ribosomal internal transcribed spacer (ITS) region as a universal DNA barcode marker for Fungi. Proc. Natl. Acad. Sci. USA 109: 6241-6246. http://dx.doi.org/10.1073/pnas.1117018109

Thiebaut F, Grativol C, Hemerly AS and Ferreira PCG (2015). MicroRNA networks in plant-microorganism interactions. Trop. Plant Biol. 8: 40-50. http://dx.doi.org/10.1007/s12042-015-9149-9

Tinoco ML, Dias BB, Dall'Astta RC, Pamphile JA, et al. (2010). In vivo trans-specific gene silencing in fungal cells by in planta expression of a double-stranded RNA. BMC Biol. 8: 27. http://dx.doi.org/10.1186/1741-7007-8-27

Underwood W (2012). The plant cell wall: a dynamic barrier against pathogen invasion. Front. Plant Sci. 3: 85. http:// dx.doi.org/10.3389/fpls.2012.00085

van Loon LC, Rep M and Pieterse CM (2006). Significance of inducible defense-related proteins in infected plants. Annu. Rev. Phytopathol. 44: 135-162. http://dx.doi.org/10.1146/annurev.phyto.44.070505.143425

Weiberg A, Bellinger M and Jin H (2015). Conversations between kingdoms: small RNAs. Curr. Opin. Biotechnol. 32: 207-215. http://dx.doi.org/10.1016/j.copbio.2014.12.025

White TJ, Bruns TD, Lee S and Taylor JW (1990). PCR protocols: a guide to methods and applications. In: Amplification and direct sequencing of fungal ribosomal RNA genes for phylogenetics (Innis MA, Gelfand DH, Sninsky JJ and White TJ, eds.). Academic Press, San Diego, 315-322.

Winston ME, Hampton-Marcell J, Zarraonaindia I, Owens SM, et al. (2014). Understanding cultivar-specificity and soil determinants of the cannabis microbiome. PLoS One 9: e99641. http://dx.doi.org/10.1371/journal.pone.0099641

Woese CR and Fox GE (1977). Phylogenetic structure of the prokaryotic domain: the primary kingdoms. Proc. Natl. Acad. Sci. USA 74: 5088-5090. http://dx.doi.org/10.1073/pnas.74.11.5088

Woese CR, Kandler O and Wheelis ML (1990). Towards a natural system of organisms: proposal for the domains Archaea, Bacteria, and Eucarya. Proc. Natl. Acad. Sci. USA 87: 4576-4579. http://dx.doi.org/10.1073/pnas.87.12.4576

Zhang DX, Nagabhyru P, Blankenship JD and Schardl CL (2010). Are loline alkaloid levels regulated in grass endophytes by gene expression or substrate availability? Plant Signal. Behav. 5: 1419-1422. http://dx.doi.org/10.4161/ psb.5.11.13395

Zhao D, Li T, Shen M, Wang J, et al. (2015). Diverse strategies conferring extreme cadmium (Cd) tolerance in the dark septate endophyte (DSE), Exophiala pisciphila: evidence from RNA-seq data. Microbiol. Res. 170: 27-35. http:// dx.doi.org/10.1016/j.micres.2014.09.005

Zhong J, Chen D, Lei XH, Zhu HJ, et al. (2014). Detection and characterization of a novel Gammapartitivirus in the phytopathogenic fungus Colletotrichum acutatum strain HNZJ001. Virus Res. 190: 104-109. http://dx.doi. org/10.1016/j.virusres.2014.05.028

Genetics and Molecular Research 15 (3): gmr.15038879 